\title{
Article \\ Ergonomic Task Analysis for Prioritization of Work-Related Musculoskeletal Disorders among Mango-Harvesting Farmers
}

\author{
Phonnipha Boriboonsuksri, Sasitorn Taptagaporn and Teeraphun Kaewdok * (D) \\ Faculty of Public Health, Thammasat University, 99 Moo 18 Paholyothin Road, Klong Luang, \\ Rangsit 12121, Thailand; phonniphab@sau.ac.th (P.B.); sasitorn.t@fph.tu.ac.th (S.T.) \\ * Correspondence: teeraphun.k@fph.tu.ac.th
}

check for updates

Citation: Boriboonsuksri, P.; Taptagaporn, S.; Kaewdok, T. Ergonomic Task Analysis for Prioritization of Work-Related Musculoskeletal Disorders among Mango-Harvesting Farmers. Safety 2022, 8, 6. https://doi.org/10.3390/ safety 8010006

Academic Editor: Raphael Grzebieta

Received: 9 November 2021 Accepted: 21 January 2022

Published: 26 January 2022

Publisher's Note: MDPI stays neutral with regard to jurisdictional claims in published maps and institutional affiliations.

Copyright: (C) 2022 by the authors. Licensee MDPI, Basel, Switzerland. This article is an open access article distributed under the terms and conditions of the Creative Commons Attribution (CC BY) license (https:// creativecommons.org/licenses/by/ $4.0 /)$.

\begin{abstract}
This paper proposes a mixed ergonomic tool analysis algorithm to prioritize work-related musculoskeletal problems. This study is a cross-sectional study assessing the prevalence of workrelated musculoskeletal disorders (WMSDs) with associated risk factors among 14 male mangoharvesting farmers (all right-handed) with the mean age of $52.28 \pm 7.75$ years. Four tasks following mango-harvesting processes were analyzed: (1) mango harvesting, (2) mango transporting, (3) mango size sorting, and (4) mango weighing and transporting to the truck. The perceived physical exertion while working on a mango-harvesting farm was based on the Borg CR-10 with a modified Standardized Nordic Questionnaire. Physical risk level due to awkward posture was evaluated by the Rapid Upper Limb Assessment (RULA), and risk due to whole-body posture in association with the level of WMSDs risk was evaluated by the Rapid Entire Body Assessment (REBA) score sheets. The subjective feelings of fatigue and posture analysis were normalized and combined using the theorem of power superposition to establish the fatigue effective index (FEI) for determining priorities to solve ergonomics-based task problems. This study indicated clearly that WMSDs are highly prevalent in mango-harvesting farmers, whereas the highest prevalence of WMSDs was reported in the right shoulder, right upper arm and lower back. The result provided the FEI of mango-harvesting farmers, ranked as follows: (1) size-sorting task, (2) weight-lifting task, (3) harvesting task, and (4) transporting task. The authors concluded that mango size sorting should be the first task to be improved to resolve the muscle fatigue problems among male mango-harvesting farmers.
\end{abstract}

Keywords: ergonomics; prioritization; musculoskeletal disorders; fatigue; posture

\section{Introduction}

Worldwide, problems with symptoms and disorders of the musculoskeletal system are becoming common among the working population [1]. Thailand has laws governing the safety of workers in the workplace [2]. Nevertheless, a study of investments in safety in Thailand found that industrial enterprises invested an average of USD 1397 per person in work safety. If unsafe circumstances occur at work, this investment can reduce costs by USD 3278 per year, or 2.35 times the investment [3]. However, the agricultural sector does not appear to have such an investment. Many studies investigated how to ensure occupational safety for agriculture workers [1,4-8]. Most studies explored the conditions of work-related musculoskeletal disorders (WMSDs) and supported the development of innovation. Moreover, the problem analysis of WMSDs in most studies focused on a specific task, analyzed the problem, and investigated the solution $[9,10]$.

Each workplace has multiple tasks/workstations, and each task/workstation has various types of risk factors for WMSDs, including the individual factors, such as age, weight, height, gender, levels of individual physical conditioning and ongoing medical conditions, such as diabetes or rheumatoid arthritis, professional activities, sport activities, domestic activities, recreational activities, alcohol/tobacco, consumption, and, previous WMSDs. The organizational factors include poor communication, lack of influence or 
control over one's job. The physical factors include awkward postures, repetitive work, forceful exertions, hand arm vibration, all-body vibration, mechanical compression, cold, force of movements. The psychosocial factors include job strain, social support at work, monotony work, rest cycle, task demands, social support, and job dissatisfaction [11-17].

Thailand is exposed to high risks of WMSDs in the neck, forearms, hands, and lower back critical areas of the body with high exposure to motion repetition, force, and extreme postures $[17,18]$. The study of Hasheminejad et al. [19] revealed a high prevalence of WMSDs of pistachio farmers and various related risk factors for elderly farmers among agricultural workers in Iran [20]. Some common WMSDs in fruit harvesting include repetitive movements, strains of the upper limbs, stooping, working hours, work experience, and worker age [1,21-23].

This reality makes the prioritization of problem solving more complex. Conceptual research frameworks covering all aspects of work, such as healthcare professional service (B-T Kart et al.) [9], have been presented. The input transformation and output models of healthcare professional performance are defined as performance-development systems, which use the conceptual research framework as performance-based input transformation processes and performance output variables. In this way, the effects of these models are illustrated, and new treatments can be formulated to reduce the impact of injuries on the muscles. However, there is also a concept that does not involve implementing process methodology to sort the risk level of employee safety or classify the problem level. Abdul Aziz et al. [24] proposed a web-based ergonomic assessment system (W-BEAS) for prioritizing critical WMSD risk factors using the analytic hierarchy structure (AHP) model, and Suarez Sanchez et al. [25] proposed using the K-nearest neighbor (KNN) technique for the classification of workers according to their risk of suffering musculoskeletal disorders. However, both techniques require a complicated procedure to operate with risk-factor conditions.

As schematized in this paper, as shown in Figure 1, the work of harvesting mangoes on a farm consists of four tasks. Each task is at risk of causing musculoskeletal disorders. To classify and solve high-risk problems, we present the implementation of performance inputs as transformation processes and then synthesize those processes with the theorem of the power superposition method, which results in a performance output in terms of the fatigue-effective index (FEI) that prioritizes the problem as the risk level to employee safety for mango-harvesting farmers. The work of harvesting mangoes on a farm consists of several tasks. Previously, most studies on WMSDs were case-by-case task analyses. However, work-related problems that accumulate over a long period are a health issue that affects the physical and mental well-being of farmers [3-8]. The awkward postures when working on the farm cause potential hazards, such as physical fatigue, highly repetitive work for a long time, and incorrect working postures. These factors can produce pain and fatigue in body regions, such as the neck, shoulders, elbows, forearm, wrists/hands, lower back, trunk, legs/ankles and foot. $[1,7,8,17,26]$. Additionally, poor workstation design was also a cause of muscular pain and injuries among the workers. In particular, poor design was associated with the highest risks in the lower back, shoulders, and upper arms. In addition, the workload was another cause underlying these risks [27-31].

The workers involved in harvesting mangos are highly susceptible to ergonomic problems due to the nature of their work and body posture. Many processes are involved in mango harvesting, mango transporting, mango size sorting, mango weighing, and transporting mangoes to the truck. Repetitive motions caused by using muscles in the same position are one of the main factors contributing to exhaustion. Thus, like any workplace, mango farming can lead to occupational-specific illness and injuries to body regions, such as the shoulder, upper arm, lower back and neck, that may need medical attention. Under the appropriate situation, the muscular strength has sufficient energy to transfer the force for working and moving the body. If the muscular strength is inadequate for the requirement of work, those muscles are weakened. When the muscle becomes injured from work overload, the efficiency for work is decreased [20-23,32-34]. This factor ultimately results in greater 
medical expenses for mango farmers. Previous studies have presented several kinds of research on WMSDs, which are the most common of all occupational non-fatal injuries and illnesses among farmworkers. Another study showed that musculoskeletal strain or the high risk of WMSDs at the neck, forearm, hand, lower back and shoulder is a significance occupational health problem affecting harvest workers [4,8,10,17,18,23-35]. In addition, ergonomists have identified ergonomic risk factors that can lead to WMSDs, including poor postures of the neck, shoulders, wrists, lower back, and knees [35-38]. For example, when the shoulder angle increases due to the working position of the electromyogram, the discomfort of the shoulder muscle also increases [35,36]. Therefore, occupational disease is an important issue for worker health and safety.

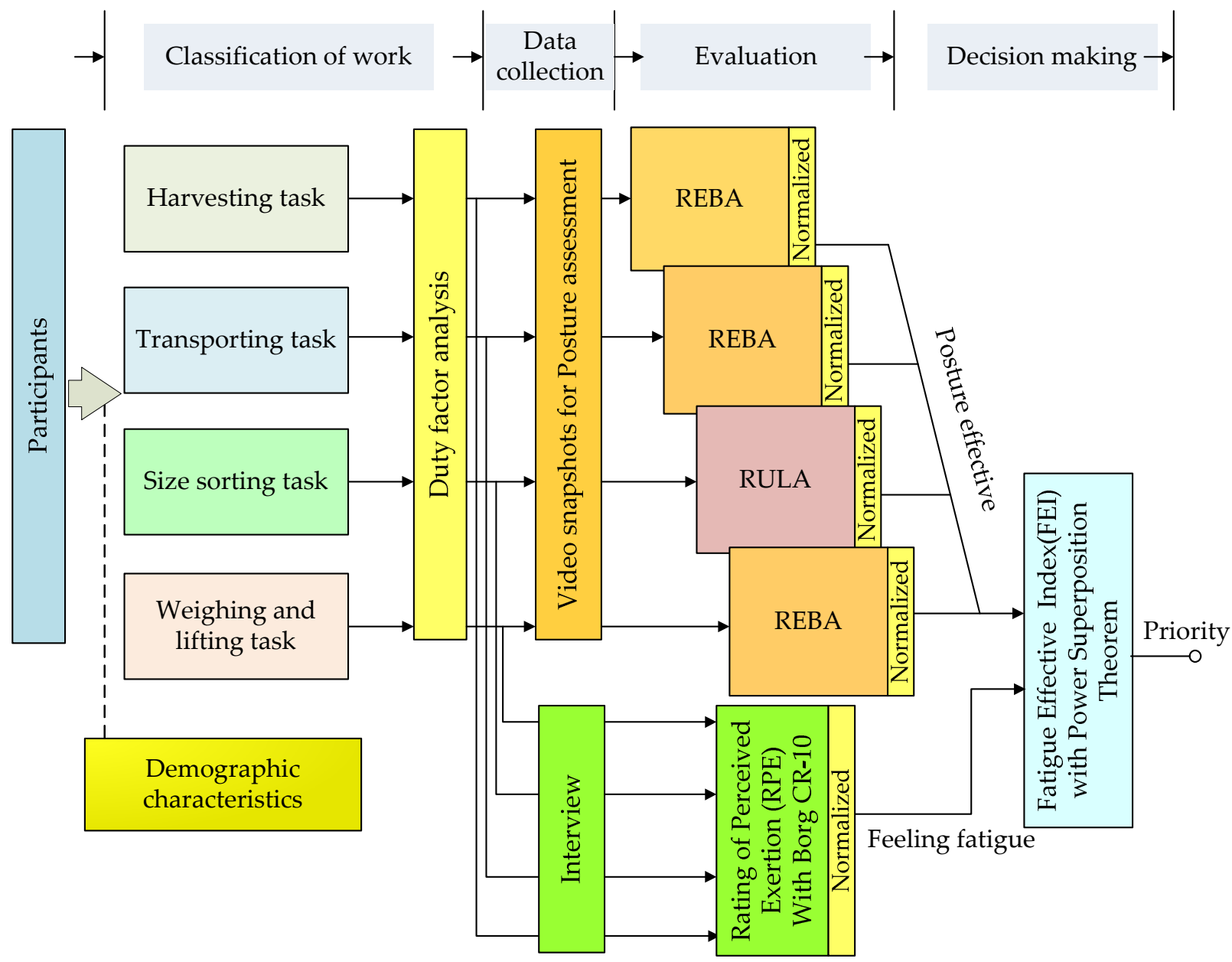

REBA: Rapid Entire Body Assessment

RULA: Rapid Upper Limp Assessment

Figure 1. Conceptual framework of a mixed ergonomic tool analysis algorithm for prioritization of WMSDs.

This study aims to use the mixed ergonomic tool analysis algorithm to prioritize WMSDs. We analyzed the Sam Phran district in Nakhon Pathom province, which is considered one of the best districts for farming activities. The flow of the Tha-Chin River through the Sam Phran district provides an advantage for growing mangoes in this area. Firstly, the constant and adequate water supply from the Tha-Chin River facilitates a higher yield of mango plants. Secondly, the canal is also used for transporting mangoes and materials. Moreover, cultivation of the Fa-Lan mango was found to be highest in 
this district. Ultimately, this research focuses on exploring the ergonomic problems and engaging in a task analysis of WMSDs among harvest workers.

\section{Materials and Methods}

\subsection{WMSDs Conceptual Framework}

A cross-sectional study was conducted on four tasks following four mango harvesting processes: (1) mango harvesting, (2) mango transporting, (3) mango size sorting, and (4) mango weighing and transporting to the truck. The conceptual framework is shown in Figure 1. The tasks were analyzed based on worker interviews using the Borg CR-10 scale and initial posture observations, recorded by the author with a video recorder, as shown in Figure 2.

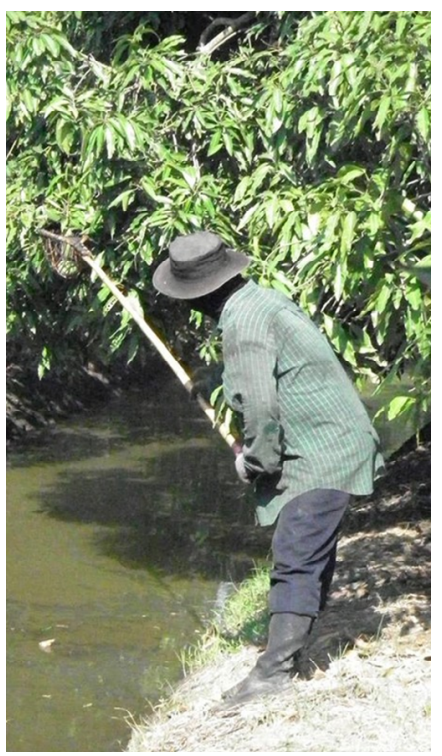

(a)

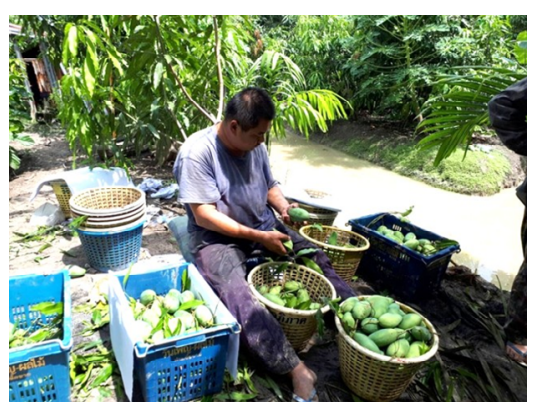

(c)

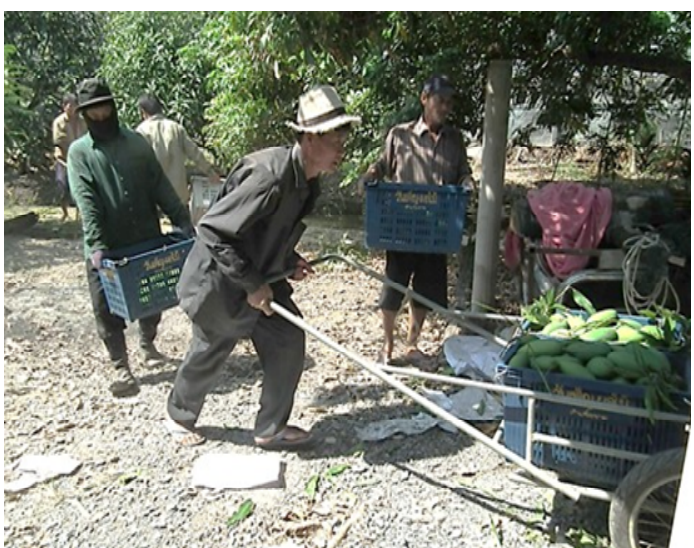

(b)

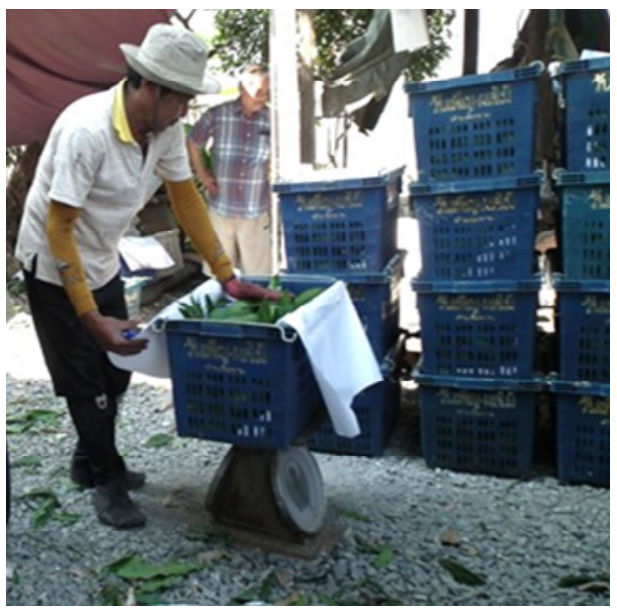

(d)

Figure 2. The four mango harvesting tasks consist of (a) mango harvesting, (b) mango transporting, (c) mango size sorting, and (d) mango weighing and transporting to the truck.

\subsection{Study Participants}

This study was performed on 14 male farmers, the age range being between 39 and 64 years, who work on a mango farm in Sam Phran District, Nakhon Pathom province. All participants were healthy and strong: no personal disease (such as heart disease, liver disease, or diabetes, body mass index over 30 were excluded, etc.), no history of musculoskeletal diseases, previous trauma, previous surgery, or accidents, rested at least $6 \mathrm{~h}$, good mental health, no history of psychological problems, and good social well-being. Before taking part in the interview, every participant was briefed about the purpose of the study. Informed consent was also obtained from all participants who took part in the study, which was approved by the Ethics Review Sub-Committee for Research Involving 
Human Research Subjects of Thammasat University, No. 3. (042/2562). The participation in the research was voluntary and participants could refuse to participate or withdraw from research at any time, without giving reasons and without losing the benefits, which did not affect the study in any way. Data were collected from September 2019 to February 2020.

\subsection{Measurement of the Variables}

This study used a four-part measurement of the variables, which we developed by reviewing the previous literature as described below.

\subsubsection{Demographic Characteristics}

This questionnaire included age, height, weight, body mass index (BMI), work experience, and working hours per day.

\subsubsection{Subjective Feeling of Fatigue (Feeling of Fatigue Variable)}

The rating of perceived exertion (RPE) allowed the participants to describe increases in the perceived intensity of their physical loads following increases in physical intensity. This part of the study was adopted from the Borg CR-10 scale used to quantify the perception of physical exertion $[39,40]$. This study examined subjective muscular fatigue in 12 body parts. The participants were requested to respond Yes or No ( 1 or 0$)$ on body parts specified on a body map. The RPE categorized scores from 0 (nothing at all) to 10 (extremely heavy). The information was obtained in the form of structured questionnaires. These forms contained questions related to subjective muscular fatigue and the Borg CR-10 scale with the modified Standardized Nordic Questionnaire [41] and were used to analyze musculoskeletal symptoms among the mango farmers. A schematic of the body regions where the participants perceived exertion, fatigue, or pain is shown in Figure 3.
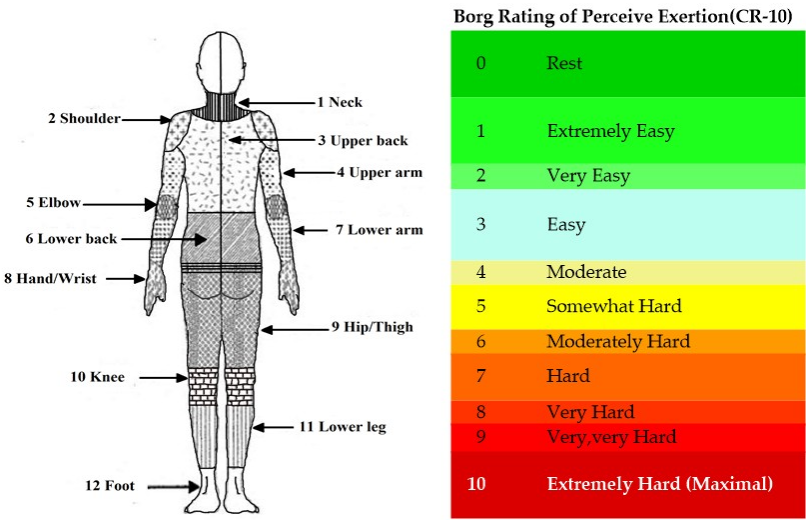

Figure 3. Schematic body regions in muscular fatigue self-reporting.

\subsubsection{Physical Risk Level Due to Awkward Posture (Posture Effective Variable)}

This part of the study investigated working postures during mango harvesting. For this process, the Rapid Upper Limb Assessment (RULA) and Rapid Entire Body Assessment (REBA) techniques were used to determine the level of ergonomic risk and the need for intervention. After recording a video, the video was cropped to obtain snapshots for the analysis of working postures. These snapshots were analyzed, and then the results were entered into the RULA and REBA worksheets.

The RULA assessment is a survey method developed for use in ergonomic investigations of workplaces, where work-related upper limb disorders are reported. This tool requires no special equipment to provide a quick assessment of the postures of the neck, trunk, and upper limbs along with muscle functions and experienced external loads. A coding system is used to generate an action list that indicates the level of the intervention required to reduce the risks of injury due to physical loading on the operator [36,42], as shown in Table 1. 
Table 1. The RULA score levels and description.

\begin{tabular}{ccc}
\hline Action Level & RULA Score & Description \\
\hline 1 & $1-2$ & Posture is acceptable. It is not maintained or repeated for too long. \\
2 & $3-4$ & Further investigation is needed, and changes may be required. \\
3 & $5-6$ & Further investigations and changes are required soon. \\
4 & 7 & Further investigations and changes are required immediately. \\
\hline
\end{tabular}

The REBA assessment is an ergonomic assessment tool that uses a systematic process to evaluate the whole-body posture, work-related musculoskeletal disorders (WMSDs), and risks associated with a work task. Using the REBA worksheet, the evaluator assigns a score for each of the following body regions: wrists, forearms, elbow, shoulders, neck, trunk, legs, and knees. After the data for each area are collected and scored, table forms are used to compile the risk-factor variables, generating a single score representing the WMSD risk level [42-44], as shown in Table 2.

Table 2. The REBA score and risk levels.

\begin{tabular}{ccc}
\hline Action Level & REBA Score & Level of WMSDs Risk \\
\hline 1 & 1 & Negligible risk. No action is required. \\
2 & $2-3$ & Low risk. Changes may be required. \\
3 & $4-7$ & Medium risk. Further investigations and changes are required soon. \\
4 & $8-10$ & High risk. Further investigations and changes are required soon. \\
5 & $11+$ & Further investigations and changes are required immediately. \\
\hline
\end{tabular}

\subsubsection{Duty Factor of Work Characteristics}

The duty factor of the work characteristics was the organizational ergonomic risk factor, produced by an imbalanced work-rest ratio. In this study, the ratio between working time and period of time was defined by the duty factor or the ratio of work loaded per unit time [45]. The duty factor is the proportion of the working time compared to the total time. The rest or break time during the work was also considered and included in the duty factor variable according to Equation (1), shown in Figure 4. To determine the need to improve mango-harvesting workstations, it was necessary to examine the muscular fatigue at all workstations. The variables of the study consist of the proportion of working time compared to the total time:

$$
\text { Duty factor }=\frac{T_{\text {Working }}}{\left(T_{\text {Working }}+T_{\text {Break }}\right)}
$$

where $T_{\text {Working }}$ is the working time, and $T_{\text {Break }}$ is the break time during work. The mangoharvesting process was investigated by observing the worker's performance for about $6 \mathrm{~h}$ per day. The duty factors in this study are as follows:

- Harvesting task

The workers had a half-an-hour break during the working period, and the working time was about $4.5 \mathrm{~h}$ per day. Thus, the duty factor was $(0.5)(4.5 / 6)=0.38$.

- Transporting task

The operation time of the transporting task was about $5 \mathrm{~h}$ per day. In this task, the mangoes were transported about two times per hour. Each transport cycle carried 15 mango crates and required about $7 \mathrm{~min}$. The duty factor was $(7 / 30)(5 / 6)=0.19$.

- $\quad$ Size-sorting task

In this task, the workers operated for $5 \mathrm{~h}$ per day and were exposed to a long-term static posture. The duty factor of this task was $(5 / 6)=0.83$. 
- Weighing and lifting task

The mango weighing working time was $6 \mathrm{~h}$ per day. The work consisted of (1) lifting the mango crates from the boat, (2) weighing the mango crates, and (3) loading the mango crates into the truck. This task was performed approximately every $15 \mathrm{~min}$ to half an hour. Thus, the duty factor was $(15 / 30)(6 / 6)=0.50$.

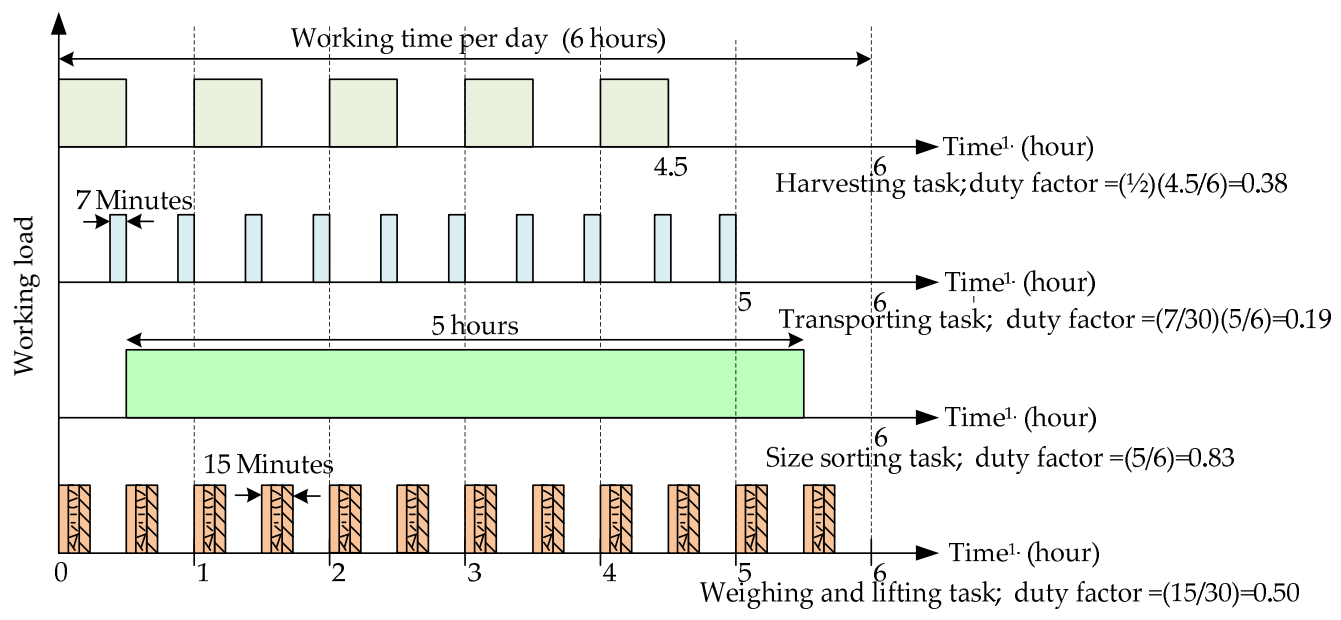

1. The horizontal axis is the time in hours

Figure 4. Duty factor of each task for mango harvesting in the Sam Phran district, Nakhon Pathom province.

All four tasks' duty factors are illustrated in the timing diagram (Figure 4).

\subsubsection{The Fatigue Effective Index (FEI)}

When analyzing work efficiency's relationship with musculoskeletal disorders, the subjective muscular fatigue and working posture effects were necessary to determine the decision-making priorities to solve ergonomic task problems. In this study, a novel method for determining the effectiveness resulting from both feeling fatigue and posture assessments was used by applying the theorem of power superposition [46].

Theorem 1. Determination of the total power dissipated in the resistor loads of a linear network demonstrates theoretically that the total power is the sum of the power supplied simultaneously by each source, while the other influencing source is disabled.

This theorem demonstrates that the total power dissipated in the load of a linear system is the summation of each power source supplied to that system. Likewise, we assume in this study that subjective muscular fatigue and affected working postures are sources of effective fatigue. The effect of fatigue due to a load on the body of the participant is due to two power sources of fatigue, which can be written as Equation (2).

$$
F E I=\sqrt{(\text { PostureEff })^{2}+(\text { FeelingFatigue })^{2}}
$$

where FEI defines the fatigue effective index (FEI) of mango-harvesting farmers' tasks that should be prioritized to solve the WMSDs problem. The parameter PostureEff is defined as the posture effect potential, and FeelingFatigue is defined as the subjective muscular fatigue potential. These strategies make solving the WMSDs problem correspond to the concept of emphasis of the equity of sources. 


\section{Results}

\subsection{Demographic and Work Characteristics}

\subsubsection{Demographic Characteristics}

Demographic characteristics are an individual ergonomic risk factor. This study was performed on 14 male farmer participants who work in mango farming and have an average age of $52.28 \pm 7.75$ years. The average height, weight, BMI, work experience and working hours per day were $167.71 \pm 5.52 \mathrm{~cm}, 63.00 \pm 6.90 \mathrm{~kg}, 22.46 \pm 2.81 \mathrm{~kg} / \mathrm{m}^{2}$, $7.64 \pm 3.03$ years, and $6.50 \pm 0.76 \mathrm{~h}$ per day respectively, as shown in Table 3 . All participants were right handed.

Table 3. Demographic data of the participants.

\begin{tabular}{ccc}
\hline Demographic Data & Mean & SD \\
\hline Age (years) & 52.29 & 7.75 \\
Weight (kilograms) & 63.00 & 6.91 \\
Height (centimeters) & 167.71 & 5.52 \\
Experience (years) & 7.64 & 3.03 \\
BMI $\left(\mathrm{kg} / \mathrm{m}^{2}\right)$ & 22.46 & 2.81 \\
\hline
\end{tabular}

\subsubsection{Rating of Perceived Exertion (RPE) with Borg CR-10}

The subjective muscular fatigue of the participants, reported as the prevalence of musculoskeletal symptoms over the past 6 months, showed that the three body regions with the highest prevalence rates of WMSDs were the right shoulder (100\%), right upper $\operatorname{arm}(100 \%)$, and right lower back (71.43\%). In this study, an ergonomic risk score of 5 or greater was considered to indicate risk. The five body parts with the highest prevalence rates of symptoms were the upper arm, shoulder, lower back, neck, and upper back, as shown in Table 4.

Table 4. Distribution of WMSDs reported in different body parts.

\begin{tabular}{ccc}
\hline Body Regions & Frequency & Percentage \\
\hline Neck & 8 & 57.14 \\
Shoulder & 14 & 100.00 \\
Upper back & 3 & 21.43 \\
Upper arm & 14 & 100.00 \\
Lower back & 10 & 71.43 \\
\hline
\end{tabular}

The participants were asked to estimate the perceived physical exertion while working in a mango-harvesting farm on a scale from 0 to 10 according to the Borg CR-10 scale. As shown in Figure 5, the three body parts with the highest perceived levels of physical exertion were the upper arm, shoulder, and lower back. The Borg CR-10 evaluation result revealed that the mango size sorting task had the highest physical exertion values, equal to 8.0 for the upper arms, 7.5 for the shoulders, and 7.0 for the lower back.

A survey was conducted with the 14 participants. The results were calculated to determine the average subjective feeling of fatigue. Analyses of the results were classified by the type of task performed, and the results are shown in Table 5. 


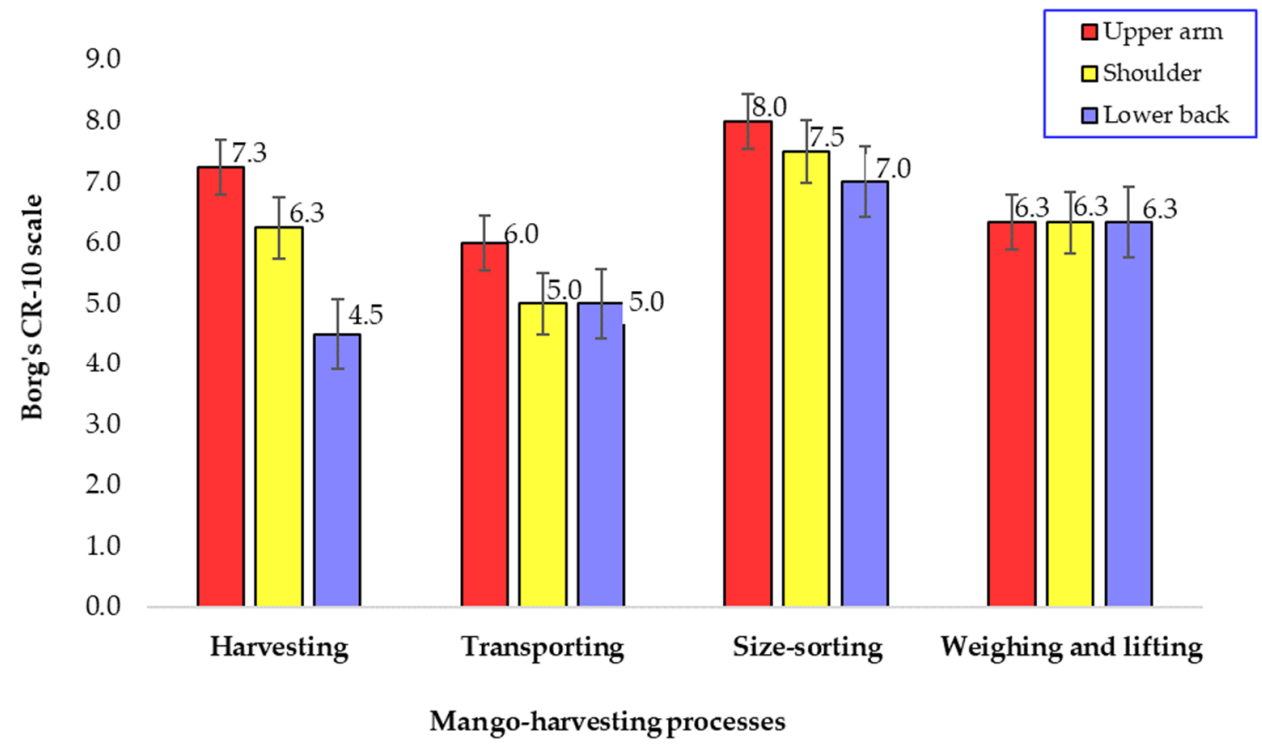

Figure 5. Perceived physical exertion while working on the mango harvesting farm.

Table 5. The subjective feeling of fatigue used to estimate the perceived physical exertion while working on a mango-harvesting farm (using the Borg CR-10 scale).

\begin{tabular}{|c|c|c|c|c|c|c|c|c|c|c|c|c|c|c|}
\hline 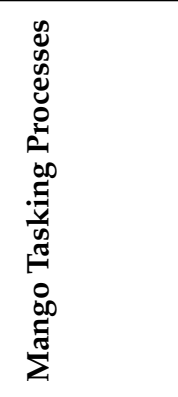 & 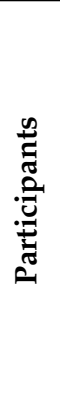 & $\begin{array}{l}\text { चै } \\
\text { Z }\end{array}$ & $\frac{\frac{t}{0}}{\frac{0}{3}}$ & 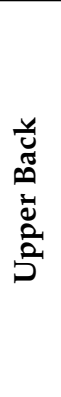 & $\begin{array}{l}\Xi \\
\vdots \\
\vdots \\
\vdots \\
\vdots \\
0 \\
0\end{array}$ & $\begin{array}{l}3 \\
0 \\
0 \\
0\end{array}$ & 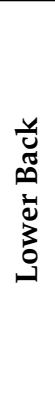 & $\begin{array}{l}5 \\
\vdots \\
\vdots \\
0 \\
0 \\
0 \\
0\end{array}$ & 点 & 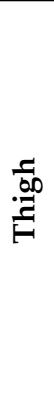 & $\underset{\Xi}{\Xi}$ & ه్త & $\begin{array}{l}\overrightarrow{0} \\
0\end{array}$ & 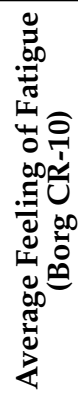 \\
\hline 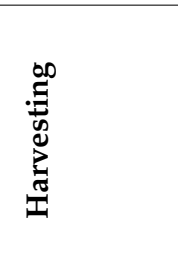 & $\begin{array}{l}1 \\
2 \\
3 \\
4 \\
5 \\
6 \\
7 \\
8\end{array}$ & $\begin{array}{l}5 \\
6 \\
5 \\
6 \\
5 \\
5 \\
6 \\
5\end{array}$ & $\begin{array}{l}7 \\
6 \\
7 \\
6 \\
6 \\
6 \\
6 \\
6\end{array}$ & $\begin{array}{l}2 \\
2 \\
3 \\
2 \\
3 \\
3 \\
2 \\
3\end{array}$ & $\begin{array}{l}7 \\
8 \\
8 \\
7 \\
7 \\
7 \\
7 \\
7\end{array}$ & $\begin{array}{l}2 \\
2 \\
2 \\
2 \\
2 \\
2 \\
2 \\
2\end{array}$ & $\begin{array}{l}4 \\
5 \\
4 \\
5 \\
5 \\
4 \\
4 \\
5\end{array}$ & $\begin{array}{l}2 \\
2 \\
3 \\
3 \\
3 \\
2 \\
3 \\
3\end{array}$ & $\begin{array}{l}3 \\
3 \\
3 \\
3 \\
2 \\
3 \\
2 \\
3\end{array}$ & $\begin{array}{l}2 \\
2 \\
2 \\
3 \\
3 \\
2 \\
3 \\
2\end{array}$ & $\begin{array}{l}2 \\
2 \\
3 \\
2 \\
2 \\
2 \\
2 \\
2\end{array}$ & $\begin{array}{l}3 \\
3 \\
2 \\
2 \\
2 \\
3 \\
2 \\
2\end{array}$ & $\begin{array}{l}2 \\
2 \\
2 \\
2 \\
2 \\
2 \\
2 \\
2\end{array}$ & $\begin{array}{l}3.42 \\
3.58 \\
3.67 \\
3.58 \\
3.50 \\
3.42 \\
3.42 \\
3.50\end{array}$ \\
\hline 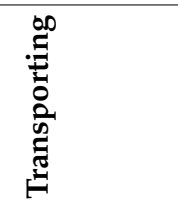 & 9 & 3 & 5 & 3 & 6 & 2 & 5 & 3 & 2 & 3 & 3 & 3 & 3 & 3.58 \\
\hline : & 10 & 3 & 8 & 4 & 8 & 2 & 7 & 3 & 2 & 2 & 3 & 2 & 2 & 3.83 \\
\hline $\begin{array}{l}\infty \\
\tilde{N} \\
\text { is }\end{array}$ & 11 & 3 & 7 & 4 & 8 & 3 & 7 & 3 & 3 & 2 & 2 & 2 & 2 & 3.83 \\
\hline 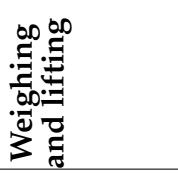 & $\begin{array}{l}12 \\
13 \\
14\end{array}$ & $\begin{array}{l}4 \\
4 \\
4\end{array}$ & $\begin{array}{l}6 \\
7 \\
6\end{array}$ & $\begin{array}{l}5 \\
5 \\
5\end{array}$ & $\begin{array}{l}6 \\
6 \\
7\end{array}$ & $\begin{array}{l}2 \\
2 \\
2\end{array}$ & $\begin{array}{l}7 \\
6 \\
6\end{array}$ & $\begin{array}{l}3 \\
3 \\
4\end{array}$ & $\begin{array}{l}2 \\
2 \\
2\end{array}$ & $\begin{array}{l}3 \\
3 \\
3\end{array}$ & $\begin{array}{l}2 \\
2 \\
2\end{array}$ & $\begin{array}{l}3 \\
3 \\
3\end{array}$ & $\begin{array}{l}3 \\
3 \\
3\end{array}$ & $\begin{array}{l}3.83 \\
3.83 \\
3.92\end{array}$ \\
\hline Count $\geq 5$ & & 8 & 14 & 3 & 14 & -1 & 10 & -1 & -1 & -1 & -1 & -1 & -1 & \\
\hline
\end{tabular}

${ }^{1}$ Not taken into account because of the score less than 5 . 


\subsubsection{Association between Risk Factors and the Feeling of Fatigue}

In this study, we carried out ordinal logistic regression analysis for factors associated with feeling of fatigue, with age, BMI, work experience and the four tasks of mangoharvesting processes as an independent variable, and the average feeling of fatigue (Borg CR-10) as a dependent variable.

For the analysis, the logarithm of odds ratio $(\beta)$ estimate associated with the average feeling of fatigue can be seen in Table 6 . The results of the ordinals logit model are significant $\left(\chi^{2}=23.164, p\right.$-value $\left.=0.001\right)$ when tested with the likelihood ratio test. The goodnessof-fit indicators of the ordinal logit model as shown with Pearson's chi square $=41.810$ $(p$-value $=0.648)$.

Table 6. Logistic model derived odds ratio (OR) for prevalence of WMSDs in the mangoharvesting processes.

\begin{tabular}{|c|c|c|c|c|}
\hline Variable & $\begin{array}{c}\text { Estimate } \\
(\beta)\end{array}$ & Wald & $\begin{array}{l}\text { Odds Ratio } \\
\text { (OR) }\end{array}$ & $p$-Value \\
\hline \multicolumn{5}{|c|}{ Threshold of Average Feeling of Fatigue (Borg CR-10) } \\
\hline$[$ Score $=3.42]$ & 31.299 & 4.391 & & 0.036 * \\
\hline$[$ Score $=3.50]$ & 33.665 & 4.580 & & 0.032 * \\
\hline$[$ Score $=3.58]$ & 38.737 & 5.174 & & 0.023 * \\
\hline$[$ Score $=3.67]$ & 53.501 & 0.001 & & 0.970 \\
\hline \multicolumn{5}{|l|}{ Risk factors } \\
\hline Age (years) & 0.089 & 0.726 & 1.093 & 0.394 \\
\hline BMI $\left(\mathrm{kg} / \mathrm{m}^{2}\right)$ & 0.770 & 2.588 & 2.160 & 0.108 \\
\hline Work experience (years) & 1.383 & 4.694 & 3.987 & 0.030 * \\
\hline Harvesting task & 1.061 & 0.117 & 2.889 & 0.733 \\
\hline Transporting task & 3.625 & 0.627 & 37.525 & 0.428 \\
\hline Size-sorting task & 48.675 & & $1.378 \times 1021$ & 0.000 * \\
\hline Weighing and lifting task (reference) & $0^{\mathrm{a}}$ & & 1.000 & \\
\hline
\end{tabular}

Note: ${ }^{\mathrm{a}}$. The reference category is weighing and lifting task. ${ }^{*} p$-value $<0.05$.

The result showed that the significance of risk factors was obtained for work experience $(\beta=1.383, p$-value $=0.03)$ and the size-sorting task $(\beta=48.675, p$-value $<0.05)$ as shown in Table 6 .

The other risk factors among participants, which indicated age $(\beta=0.089, p$-value $=0.394)$ and BMI $(\beta=0.770, p$-value $=0.108)$, showed the probability of feeling fatigue as compared to other risk factors.

The four tasks of the mango-harvesting processes associated with the average feeling of fatigue, illustrated in Figure 6, in comparison with the weighing and lifting task showed that the highest of the estimate $(\beta)$ is the size-sorting task with $\beta=48.675$.

The harvesting task and transporting task were associated with feeling greater fatigue than the weighing and lifting task, with $\beta=1.061$ and 3.625, respectively.

The static postures employed in mango size sorting were used to evaluate the risk factor score using RULA, and provided an average score of 7.0, which indicated that this workstation required immediate changes. The risk factor scores of dynamic postures, such as those used in the mango-weighing task, harvesting task, and mango-transporting task, were evaluated with the risk factor score using REBA, and the results provided average scores of 8.33, 8.25, and 6, respectively. The REBA score indicated a high-risk level for the mango-weighing task and the harvesting task and a medium risk level for the mango transporting task, as shown in Table 7. 


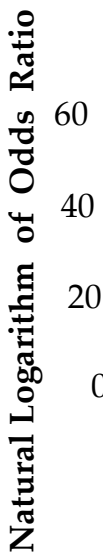

Harvesting task

Transporting task

Size-sorting task

Weighing and

lifting task (Ref.)

\section{Four tasks of the mango-harvesting processes}

Figure 6. The natural logarithm of odds ratio (Log. Odds) estimates for the four tasks of mangoharvesting processes.

Table 7. The results of the fatigue study of mango-harvesting workers.

\begin{tabular}{|c|c|c|c|c|c|c|c|c|c|c|c|c|c|c|}
\hline 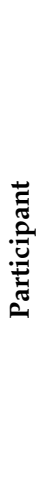 & 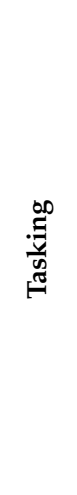 & 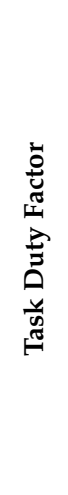 & 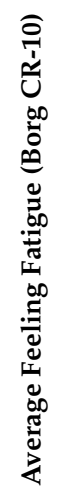 & 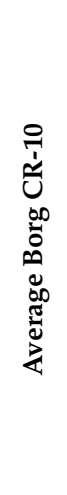 & 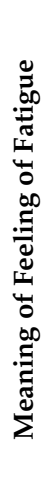 & 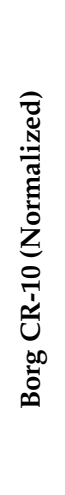 & 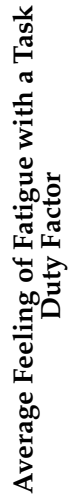 & 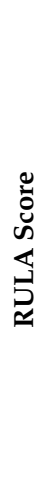 & 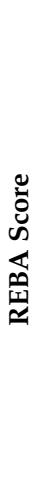 & & & 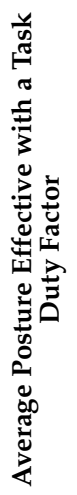 & 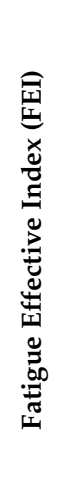 & 롤 \\
\hline $\begin{array}{l}1 \\
2 \\
3 \\
4 \\
5 \\
6 \\
7 \\
8\end{array}$ & 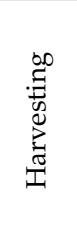 & $\begin{array}{l}0.38 \\
0.38 \\
0.38 \\
0.38 \\
0.38 \\
0.38 \\
0.38 \\
0.38\end{array}$ & $\begin{array}{l}3.42 \\
3.58 \\
3.67 \\
3.58 \\
3.50 \\
3.42 \\
3.42 \\
3.50\end{array}$ & 3.51 & 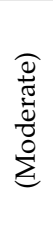 & $\begin{array}{l}0.34 \\
0.36 \\
0.37 \\
0.36 \\
0.35 \\
0.34 \\
0.34 \\
0.35\end{array}$ & 0.13 & $\begin{array}{l}- \\
- \\
- \\
- \\
- \\
- \\
- \\
-\end{array}$ & $\begin{array}{l}8 \\
8 \\
8 \\
8 \\
8 \\
9 \\
9 \\
8\end{array}$ & 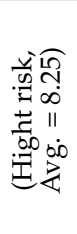 & $\begin{array}{l}0.67 \\
0.67 \\
0.67 \\
0.67 \\
0.67 \\
0.75 \\
0.75 \\
0.67\end{array}$ & 0.26 & 0.26 & 3rd \\
\hline 9 & 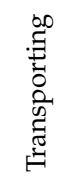 & 0.19 & 3.58 . & 3.58 & 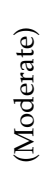 & 0.36 & 0.07 & - & 6 & 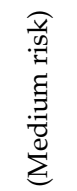 & 0.50 & 0.10 & 0.12 & 4th \\
\hline $\begin{array}{l}10 \\
11\end{array}$ & 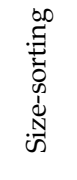 & $\begin{array}{l}0.83 \\
0.83\end{array}$ & $\begin{array}{l}3.83 \\
3.83\end{array}$ & 3.83 & 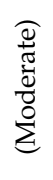 & $\begin{array}{l}0.38 \\
0.38\end{array}$ & 0.32 & $\begin{array}{l}7 \\
7\end{array}$ & - & 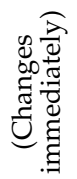 & $\begin{array}{l}1.00 \\
1.00\end{array}$ & 0.83 & 0.89 & 1st \\
\hline $\begin{array}{l}12 \\
13\end{array}$ & 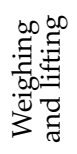 & $\begin{array}{l}0.50 \\
0.50 \\
0.50\end{array}$ & $\begin{array}{l}3.83 \\
3.83 \\
3.92\end{array}$ & 3.86 & 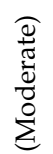 & $\begin{array}{l}0.38 \\
0.38 \\
0.39\end{array}$ & 0.19 & - & 9 & 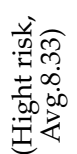 & $\begin{array}{l}0.75 \\
0.67 \\
0.67\end{array}$ & 0.35 & 0.40 & 2nd \\
\hline
\end{tabular}




\subsubsection{Posture Analysis}

To prioritize solving the task problem, all risk-level outputs of each measure were transformed into a per-unit scale, using the normalization process, and calibrated into real working time by multiplying the results with the duty factor. The outputs of the RULA and REBA of each task were averaged and transformed into the posture effective variable, indicating the physical risk level due to awkward postures. The outputs of Borg CR-10 were also averaged and transformed into the feeling-fatigue variable. Both variables were transformed from a potential to the power scale by using the squaring algorithm. The powers were then summed using the power superposition concept. Finally, the summed power results were inverse transformed into the potential scale by using the square-root procedure outlined in Equation (1). This output was defined by the FEI. Based on the FEI, this study on prioritization determined the tasks that produced the greatest muscular fatigue among workers, as follows: mango-size-sorting task (0.89), mango-weighing task (0.40), mango-harvesting task (0.26), and mango-transporting task (0.12), as shown in Table 7.

\subsubsection{Relationships with the Fatigue Effective Index (FEI)}

The subjective feeling fatigue and posture effect and the resulting correlation coefficients indicated a statistically significant association between the subjective feeling fatigue, posture effectiveness, and the effective fatigue index, as shown in Table 8.

Table 8. The correlation coefficient for the subjective feeling fatigue, posture effectiveness, and the effective fatigue index (FEI).

\begin{tabular}{cccc}
\hline Variables & Feeling of Fatigue & Posture Eff & FEI \\
\hline Feeling Fatigue & 1.000 & 0.981 & $0.984(p$-value $=0.016)$ \\
Posture Eff & $0.981(p$-value $=0.019)$ & 1.000 & $0.999(p$-value $=0.001)$ \\
FEI & 0.984 & 0.999 & 1.000 \\
\hline
\end{tabular}

The graphic in Figure 7 illustrates the relative normalized score of the four tasks while working on mango harvesting. In this study, the FEI result was a new variable that resulted from the power summation concept of two different domains of risk factor variables: subjective feeling of fatigue and posture influence. The FEI was calculated based on the effective combination concept. The FEI presented a combination concept that is much more effective than the average. The FEI score value was influenced by the potential of each power combination input. The results showed a good relationship under the correlation coefficient estimation method, as shown in Table 8 and Figure 7. Moreover, it was found that its greater compactness and simplicity compared to estimating via the correlation coefficient and the FEI can be applied to prioritize the critical WMSDs, also shown in $[24,25]$. 


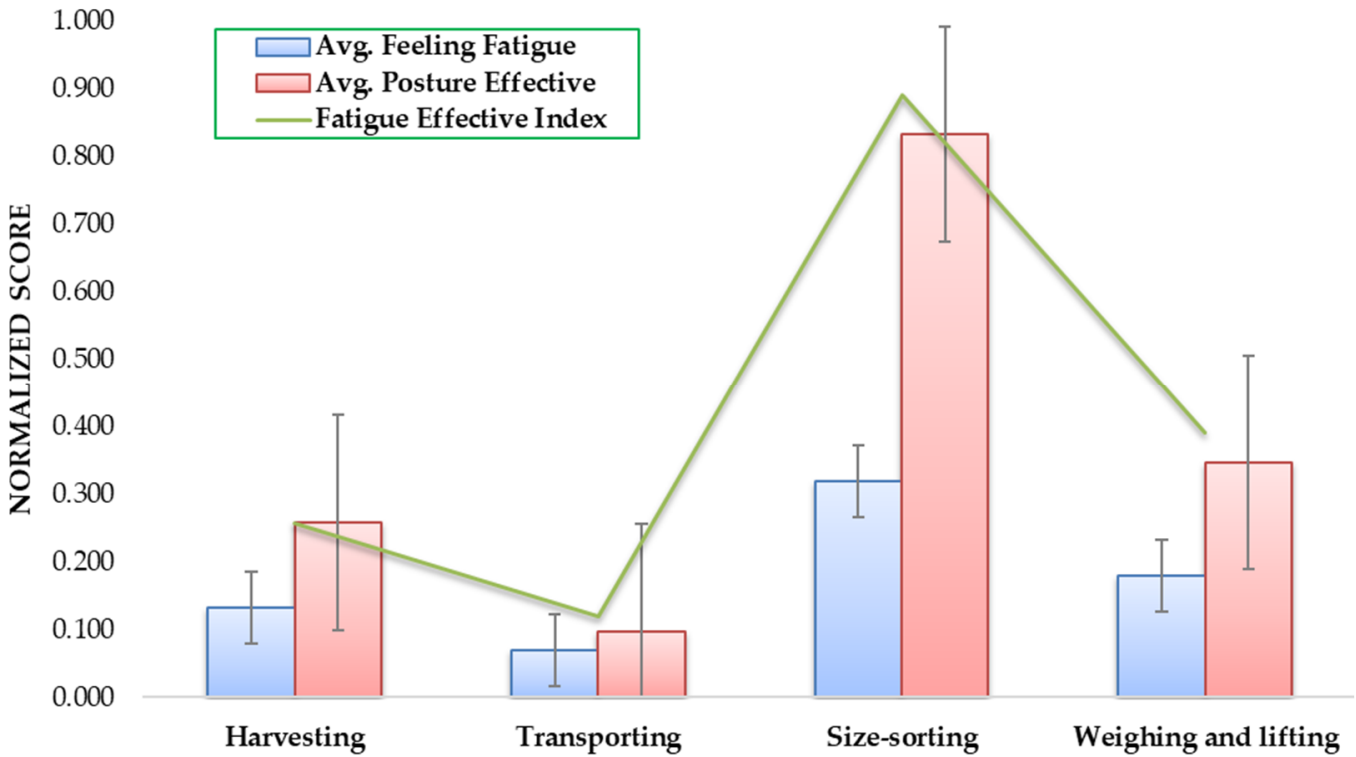

Figure 7. The relative normalized scores of four tasks while working on mango-harvesting processes.

\section{Discussion}

Awkward postures cause musculoskeletal disorders, including fatigue among workers or farmers, for which it is necessary to investigate and improve the problem of WMSDs [4-8]. In this study, a novel technique was proposed to determine high risks and solve the problem for WMSDs among mango-harvesting farmers via an integrated mixed-method analysis of the subjective feeling of fatigue (Borg CR-10) and affected working postures (RULA and REBA) [22,39-42,44,47]. Analysis of the subjective feelings of fatigue, as shown in Table 7 , found that the weighing and lifting task caused fatigue with the highest values, with the considered part of real-time working. However, in this case, all of tasks were averaged by the workload with the duty factor. Hence, the results of the subjective feeling of fatigue revealed the dominant task to be mango size sorting. In addition, the results of the prevalence of the subjective feeling of fatigue (Borg CR-10) showed the most frequent WMSDs at the right shoulder and the right upper arm. Therefore, the logistic regression analysis results, associated with the subjective feeling of fatigue with individual and workrelated factors, are as follows:

(1) Age of the participants had a sensitivity with the average feeling fatigue score with OR $=1.093, p$-value $=0.394$.

(2) BMI of the participants had a sensitivity with the average feeling fatigue score with $\mathrm{OR}=2.160, p$-value $=0.108$.

(3) Work experience of the participants had a sensitivity with the average feeling fatigue score with $\mathrm{OR}=3.987, p$-value $=0.030$.

(4) The probability of the average feeling fatigue on four tasks reference with weighing and lifting tasks can be rated by the (1st) size-sorting task, (2nd) transporting task, and (3rd) harvesting task, respectively.

For posture analysis, mango size sorting was the dominant task, with a RULA score of 7 , which means that the workstation required immediate changes.

RULA assessment was chosen for the mango size-sorting task because RULA is appropriate for long work-cycle postures with a static workload. REBA assessment was used for mango harvesting, transporting, and weighing tasks, as REBA is a postural analysis tool sensitive to musculoskeletal risks in a variety of tasks with dynamic workloads. The workers were found to be under moderate-to-high risk of musculoskeletal disorders. The RULA and REBA assessments indicated that the workers were working above a certain limit. RULA determined that the majority of the workers were under high risk levels and 
required immediate changes. REBA indicated that some of the workers were under lower risk levels, but most were still at high risk levels [22,42,43,47].

The final scores of the RULA and REBA assessments were different. Therefore, the normalization scale was adjusted to allow for comparisons of each working task to evaluate the risk of the four tasks, which have differences in duty cycles. The real workloads were calculated by multiplying the score with the duty factor. The results showed that the highest prevalence of WMSDs and muscular fatigue occurred in the mango size-sorting task because the farmers were exposed to repetitive motion injuries while working for long hours. Some of the risks associated with mango size-sorting were (1) right upper-arm pain, (2) right-shoulder pain, and (3) right lower-back pain. The impact of each task on WMSDs was analyzed, using power superposition, combining the principle of awkward posture (REBA, RULA) score and the perceived physical exertion (Borg CR-10) score, called the FEI. Each factor was not the average for the equality (the posture assessment and the feeling of fatigue), but combined, it was effective for solving the WMSDs problem.

The mango-harvesting processes with the highest risks of MSDs were as follows: (1st) size sorting, (2nd) weighing and lifting, (3rd) harvesting, and (4th) transporting with the FEI, respectively. The FEI indicated a good relationship between the subjective feeling of fatigue and posture analysis with the correlation coefficient of $0.984(p$-value $=0.016)$ and 0.999 ( $p$-value $=0.001)$, respectively. The size-sorting task was ranked the first of WMSDs in mango-harvesting processes. When analyzed, the physiology/biomechanics found several causes, such as (1) the working hours being a long time period per day, (2) the static loading condition, (3) the repetitive work, (4) the cooperation and the synchronization between eyes and hands working, (5) and the awkward posture of moving to pick up weight while sitting. The other tasks had a rest time cycle, as illustrated in the timing diagram in Figure 4. Hence, these disorders were affected by improper workstation designs that promote unsuitable positioning of the body due to the absence of principles of biomechanics or mechanical data on farming being applied in the workstation design $[22,29,30,37,38]$. In order to reduce health problems and injuries among the farmers, an ergonomic workstation design should be implemented [27-30]. If the muscular strength is inadequate for the requirements of the work, the muscles are too weak. When the muscle becomes injured from work overload, the work efficiency decreases [17-22,34,35].

\section{Conclusions}

The study investigated ergonomic task problems for the prioritization of WMSDs among mango-harvesting farmers at Nakhon Pathom province, Thailand, using a modified method analysis consisting of (i) the subjective feeling of fatigue (Borg CR-10) and (ii) posture analysis using RULA and REBA. The output of both scores were normalized and combined with the power superposition theorem for ranking the risk of WMSDs. The results of Borg CR-10 showed the most prevalence pains were in the areas of the right shoulder $(100 \%)$, right upper arm $(100 \%)$ and lower back $(71.43 \%)$ The risk factor that was significantly associated with the average Borg CR-10 was work experience $(\mathrm{OR}=0.030$, $95 \% \mathrm{CI}=1.14-13.93)$. The posture analysis based on the FEI of mango-harvesting farmers ranked the following: (1st) size-sorting task (0.89), (2nd) weight-lifting task (0.40), (3rd) harvesting task (0.26), and (4th) transporting task (0.12), respectively. As the FEI has greater compactness and simplicity, it can be applied to prioritize the criticality of WMSDs effectively.

The present study results found that repetitive tasks over a long period of time were also a common cause of injury, especially in the mango size-sorting task. Workers have to continuously visually inspect their work in a static sitting posture over the entire working period. It is necessary to find a way to prioritize the WMSDs problem. Consequently, an ergonomic assessment is, thus, essential for identifying and reducing the risks involved in physical work and increasing productivity. Therefore, mango size sorting should be the first task to be improved by proper ergonomic interventions with a man-machine system to resolve muscular fatigue problems among mango-harvesting farmers. 


\section{Limitations}

The current study was cross sectional in design, which avoided an assessment of the connection between cause and effect. Therefore, further longitudinal research is needed. The low number of participants and study areas are also limitations of the current study. Therefore, further study should add other participants and other study areas, which may strengthen the understanding of the prioritization of WMSDs.

Author Contributions: Conceptualization, P.B., S.T. and T.K.; methodology, P.B., S.T. and T.K.; tools, P.B.; validation, P.B., S.T. and T.K.; formal analysis, P.B.; investigation, P.B.; resources, P.B.; data curation, P.B.; writing-original draft preparation, P.B.; writing-review and editing, P.B.; visualization, P.B.; supervision, P.B., S.T. and T.K.; project administration, P.B. All authors have read and agreed to the published version of the manuscript.

Funding: This research received no external funding.

Institutional Review Board Statement: This research was approved by the Ethics Review SubCommittee for Research Involving Human Research Subjects of Thammasat University, No. 3 $(042 / 2562)$

Informed Consent Statement: All participants are farmers working on mango farms in the Sam Phran district, Nakhon Pathom province, and they provided written informed consent for all datacollection processes.

Data Availability Statement: Not applicable.

Acknowledgments: The authors are grateful to all the participants who kindly cooperated and written informed consent for all data collection processes until the completion of this study.

Conflicts of Interest: No potential conflict of interest is reported by the authors.

\section{References}

1. Barneo-Alcántara, M.; Díaz-Pérez, M.; Gómez-Galán, M.; Carreño-Ortega, Á.; Callejón-Ferre, Á.J. Musculoskeletal Disorders in Agriculture: A Review from Web of Science Core Collection. Agronomy 2021, 11, 2017. [CrossRef]

2. Occupational Safety, Health and Environment ACT B.E. 2554 (A.D. 2011). Available online: https://www.ilo.org/dyn/natlex/ docs/MONOGRAPH/89337/113912/F-1856355403/THA89337\%20Eng\%202.pdf (accessed on 3 July 2020).

3. Luangjinda, C.; Ritthichai, T.; Khatha, S.; Laowatthanaroj, P. An Economic Value Study on Decrease in Accident Statistics in Enterprises Participating in Establishment Development Projects; Thailand Institute of Occupational Safety and Health (TOSH): Bangkok, Thailand, 2020; pp. 81-86.

4. Kee, D.; Haslam, R. Prevalence of work-related musculoskeletal disorders in agriculture workers in Korea and preventative interventions. Work 2019, 64, 763-775. [CrossRef] [PubMed]

5. Kirkhorn, S.R.; Earle-Richardson, G.; Banks, R.J. Ergonomic risks and musculoskeletal disorders in production agriculture: Recommendations for effective research to practice. J. Agromed. 2010, 15, 281-299. [CrossRef] [PubMed]

6. Surabhi, S.; Renu, A. Ergonomic intervention for preventing musculoskeletal disorders among farm women. J. Agric. Sci. 2010, 1, 61-71.

7. Lefteris, B.; Dimitrios, T.; Dionysis, B. A review on ergonomics in agriculture. Part I: Manual operation. Appl. Sci. 2020, 10, 1905. [CrossRef]

8. Meyers, J.M.; Faucett, J.; Tejeda, D.G.; Kabashima, J.; Miles, J.A.; Janowitz, I.; Duraj, V.; Smith, R.; Weber, E. High risk tasks for musculoskeletal disorders in agricultural field work. Proc. Hum. Factors Ergon. Soc. Annu. Meet. 2000, 44, 616-619. [CrossRef]

9. Karsh, B.T.; Holden, R.J.; Alper, S.J.; Or, C.K. A human factors engineering paradigm for patient safety: Designing to support the performance of the healthcare professional. Qual. Saf. Health Care 2006, 15, 59-65. [CrossRef]

10. Earle-Richardson, G.; Jenkins, P.L.; Strogatz, D.; Bell, E.M.; Sorensen, J.A.; May, J.J. Orchard evaluation of ergonomically modified apple bucket. J. Agromed. 2006, 11, 95-105. [CrossRef]

11. Aziz, R.A.; Rebi, M.A.T.; Rani, A.; Rohani, J.M. Work-related musculoskeletal disorders among assembly workers in Malaysia. J. Occup. Saf. Health 2014, 11, 33-38.

12. De Magistris, G.; Micaelli, A.; Evrard, P.; Andriot, C.; Savin, J.; Gaudez, C.; Marsot, J. Dynamic control of DHM for ergonomic assessments. J. Ind. Ergon. 2013, 43, 170-180. [CrossRef]

13. Guimaraes, L.B.; Ribeiro, J.L.; Renner, J.S.; De Oliveira, P.A. Worker evaluation of a macro ergonomic intervention in a Brazilian footwear company. Appl. Ergon. 2014, 45, 923-935. [CrossRef] [PubMed]

14. Zare, M.; Bodin, J.; Cercier, E.; Brunet, R.; Roquelaure, Y. Evaluation of ergonomic approach and musculoskeletal disorders in two different organizations in a truck assembly plant. J. Ind. Ergon. 2015, 50, 34-42. [CrossRef] 
15. Oakman, J.; Macdonald, W.; Wells, Y. Developing a comprehensive approach to risk management of musculoskeletal disorders in non-nursing health care sector employees. Appl. Ergon. 2014, 45, 1634-1640. [CrossRef] [PubMed]

16. Subramaniam, S.; Murugesan, S. Investigation of work-related musculoskeletal disorders among male kitchen workers in South India. J. Occup. Saf. Ergon. 2015, 21, 524-531. [CrossRef] [PubMed]

17. Thetkathuek, A.; Meepradit, P.; Sa-Ngiamsak, T. A Cross-sectional Study of Musculoskeletal Symptoms and Risk Factors in Cambodian Fruit Farm Workers in Eastern Region, Thailand. Saf. Health Work 2018, 9, 192-202. [CrossRef]

18. Chaiklieng, S.; Poochada, W.; Suggaravetsiri, P. Work-related diseases among agriculturists in Thailand: A systematic review. Songklanakarin J. Sci. Technol. 2021, 43, 638-647.

19. Hasheminejad, N.; Choobineh, A.; Mostafavi, R.; Tahernejad, S.; Rostami, M. Prevalence of musculoskeletal disorders, ergonomics risk assessment and implementation of participatory ergonomics program for pistachio farm workers. Med. Lav. 2021, 112, 292-305.

20. Momeni, Z.; Choobineh, A.; Razeghi, M.; Ghaem, H.; Azadian, F.; Daneshmandi, H. Work-related Musculoskeletal Symptoms among Agricultural Workers: A Cross-sectional Study in Iran. J. Agromed. 2020, 25, 339-348. [CrossRef]

21. Mlotek, M.; Kuta, Ł.; Stopa, R.; Komarnicki, P. The Effect of Manual Harvesting of Fruit on the Health of Workers and the Quality of the Obtained Produce. Procedia Manuf. 2015, 3, 1712-1719. [CrossRef]

22. Jain, R.; Meena, M.L.; Dangayach, G.S.; Bhardwaj, A.K. Association of risk factors with musculoskeletal disorders in manualworking farmers. Arch. Environ. Occup. Health 2018, 73, 19-28. [CrossRef]

23. Lee, K.S.; Kim, K.R.; Kim, H.C.; Chae, H.S.; Kim, S.W.; Seo, M.T. Development and Evaluation of rollator for elderly farmers. J. Ergon. Soc. Korea 2014, 33, 487-497. [CrossRef]

24. Abdul Aziz, F.; Ghazalli, Z.; Mohamed, N.M.Z. A web-based ergonomics assessment system for prioritizing critical work-related musculoskeletal disorders risk factor. IOP Conf. Ser. Mater. Sci. Eng. 2020, 788, 1-16. [CrossRef]

25. Suarez Sanchez, A.; Iglesias-Rodriguez, F.J.; Riesgo Fernandez, P.; De Cos Juez, F.J. Applying the K-nearest neighbor technique to the classification of workers according to their risk of suffering musculoskeletal disorders. Int. J. Ind. Erg. 2016, 52, 92-99. [CrossRef]

26. Meyers, J.M.; Miles, J.A.; Faucett, J.; Janowitz, I.; Tejeda, D.G.; Weber, E.; Smith, R.; Garcia, L. Priority risk factors for back injury in agricultural fieldwork: Vineyard ergonomics. J. Agromed. 2004, 9, 433-448.

27. Pranav, P.K.; Patel, T. Impact of ergonomic intervention in manual orange harvester among the workers of hilly region in India. Work 2016, 54, 179-187. [CrossRef]

28. Yusoff, I.S.M.; Tamrin, S.B.M.; Aini, M.A.T.; Ng, Y.G.; Ippei, M. Oil Palm Workers: Designing Ergonomics Harvesting Tool Using User-Centered Design Approach to Reducing Awkward Body Posture by Catia Simulation. Iran. J. Public Health 2014, 43, 72-80.

29. Mokarami, H.; Varmazyar, S.; Kazemi, R.; Taghavi, S.M.; Stallones, L.; Marioryad, H.; Farahmand, F. Low cost ergonomic interventions to reduce risk factors for work-related musculoskeletal disorders during dairy farming. Work 2019, 64, 195-201. [CrossRef]

30. Giulia, E.; Paul, J.; Scott, F.; Christine, M.; Patrick, B.; John, M. An ergonomic intervention to reduce back strain among apple harvest workers in New York State. J. Appl. Ergon. 2005, 36, 327-334.

31. Fathallah, F.A. Musculoskeletal disorders in labor-intensive agriculture. Appl. Ergon. 2010, 41, 738-743. [CrossRef]

32. Houshyar, E.; Kim, I.J. Understanding musculoskeletal disorders among Iranian apple harvesting laborers: Ergonomic and stopwatch time studies. Int. J. Ind. Ergon. 2018, 67, 32-40. [CrossRef]

33. Kang, M.Y.; Lee, M.J.; Chung, H.; Shin, D.H.; Youn, K.W.; Im, S.H.; Chae, H.S.; Lee, K.S. Musculoskeletal Disorders and Agricultural Risk Factors Among Korean Farmers. J. Agromed. 2016, 21, 353-363. [CrossRef] [PubMed]

34. Kumar, P.; Chakrabarti, D.; Patel, T.; Chowdhuri, A. Work-related pains among the workers associated with pineapple peeling in small fruit processing units of North East India. Int. J. Ind. Ergon. 2016, 53, 124-129. [CrossRef]

35. Lim, C.M.; Jung, M.C.; Kong, Y.K. Evaluation of upper-limb body postures based on the effects of back and shoulder flexion angles on subjective discomfort ratings, heart rates and muscle activities. Ergonomics 2011, 54, 849-857. [CrossRef] [PubMed]

36. McAtamney, L.; Nigel Corlett, E. RULA: A survey method for the investigation of work-related upper limb disorders. Appl. Ergon. 1993, 24, 91-99. [CrossRef]

37. Davis, K.G.; Kotowski, S.E. Understanding the ergonomic risk for musculoskeletal disorders in the United States agricultural sector. Am. J. Ind. Med. 2007, 50, 501-511. [CrossRef] [PubMed]

38. Kotowski, S.E.; Davis, K.G.; Kim, H.; Lee, K.S. Identifying risk factors of musculoskeletal disorders on Korean farms. Work 2014 49, 15-23. [CrossRef] [PubMed]

39. Borg, G.A. Psychophysical bases of perceived exertion. Med. Sci. Sports Exerc. 1982, 14, 377-381. [CrossRef]

40. Borg, G.A. Psychophysical scaling with applications in physical work and the perception of exertion. Scand. J. Work Environ. Health 1990, 16, 55-58. [CrossRef]

41. Kuorinka, I.; Jonsson, B.; Kilbom, A.; Vinterberg, H.; Biering-Sorensen, F.; Andersson, G.; Jorgensen, K. Standardised Nordic questionnaires for the analysis of musculoskeletal symptoms. Appl. Ergon. 1987, 18, 233-237. [CrossRef]

42. Ansari, N.A.; Mohammad, J.S. Evaluation of work Posture by RULA and REBA: A Case Study. IOSR J. Mech. Civ. Eng. 2014, 11, 18-23. [CrossRef]

43. A Step-by-Step Guide Rapid Entire Body Assessment (REBA). Available online: http://ergo-plus.com/wp-content/uploads/ REBA-A-Step-by-Step-Guide.pdf (accessed on 1 June 2019). 
44. Songsaeng, W.; Siriwong, W. Work-related musculoskeletal disorders among coffee harvesters in Chiang Rai, Thailand: Prevalence, severity, and risk factors. J. Health Res. 2018, 32, S112-S120.

45. Kuta, L.; Jozef, C.; Izabela, G. Assessment of workload on musculoskeletal system of milkers in mechanical milking through the use of job strain index method. J. Sci. Direct. 2015, 15, 249-254.

46. Ivo, B. A Theorem on Power Superposition in Resistive Networks, in IEEE Transactions on Circuits and Systems II. Express Briefs 2021, 68, 2362-2363.

47. Li, Z.; Zhang, R.; Lee, C.-H.; Lee, Y.-C. An Evaluation of Posture Recognition Based on Intelligent Rapid Entire Body Assessment System for Determining Musculoskeletal Disorders. Sensors 2020, 20, 4414. [CrossRef] [PubMed] 